Ärztliche Erfahrung beschränkt sich nicht auf medizinisches Fachwissen. Sie entsteht auch aus den mehr oder minder alltäglichen, heiter, ärgerlich oder nachdenklich stimmenden Erlebnissen mit Patienten, Kollegen und Mitarbeitern. Senden Sie uns Ihre Geschichte an: Brigitte.Moreano@springer.com. Für jeden veröffentlichten Text erhalten Sie bis zu 100 Euro.

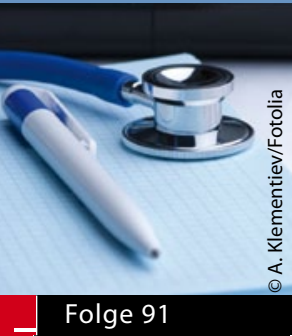

\title{
Wer hat denn hier den Doktor bestellt?
}

- Es war wieder einmal Grippezeit. Das Wartezimmer war voll und die Hausbesuche sehr zahlreich. Auf unserer Hausbesuchstour betraten meine Arzthelferin und ich eine Patientenwohnung. Ich stellte mich vor und fragte gleich nach der erkrankten Ehefrau. „Meine Lebensgefährtin, die liegt dahinten im Schlafzimmer".

Wir gingen strammen Schrittes ins Schlafzimmer. Die Helferin hatte - während ich die Anamnese erhob - schon den Koffer ausgepackt und reichte mir die Instru- mente. Es erfolgte eine gründliche Untersuchung: Thoraxorgane, Racheninspektion etc.

Zum Abschluss der Untersuchung konnte ich mir die etwas vorwurfsvolle Bemerkung nicht verkneifen: „Wissen Sie, bei diesem Befund hätten Sie aber auch in die Sprechstunde kommen können!" Die Patientin etwas konsterniert: „Ja - aber, aber ich habe doch gar keinen Arzt bestellt".

Erst jetzt klärte sich der Irrtum auf: eine falsche Hausnummer. Mit einer aufrich- tigen Entschuldigung verließen wir die Wohnung und waren schon beim nächsten Hausbesuch, diesmal bei der richtigen Adresse.

Warum hatten uns die beiden nicht gleich darauf aufmerksam gemacht, dass sie gar keinen Hausbesuch bestellt hatten? Vermutlich hat der eine Partner geglaubt, der andere hätte den Arzt gerufen. Eine solch peinliche Situation hat sich zum Glück nie mehr wiederholt.

Dr. med. JüRgen HeimanN, Dieburg .

\section{Ein grantiger Taxifahrer und zwei Todesfälle}

- Seit mehreren Jahren betreute ich ein Geschwisterpaar, das sich seit langer Zeit im Rheinmaingebiet niedergelassen hatte, aber aus dem tiefsten Oberbayern stammte. Es waren zwei liebe, aber auch recht wunderliche Leutchen, die schon häufig meine Hilfe in Anspruch genommen hatten. Sie hatte schweres Asthma und eine Herzinsuffizienz, er eine schwere Polyarthrose, trug einen ICD-Schrittmacher und war dem Tod schon mehrmals von der Schippe gesprungen.

In diesem schweren Winter ging es der Patientin äußerst schlecht. Sie konnte das Haus nicht verlassen. Einkäufe und insbesondere den Weg zur Bank musste der Mann alleine erledigen.

Der Weg zur Bank war nicht sehr weit, unter zwei Kilometer, konnte aber wegen der winterlichen Straßenverhältnisse von dem alten Mann nur mit dem Taxi zurückgelegt werden Da Taxifahrer über eine der- art kurze Fahrt meist nicht begeistert sind, hoffte der Patient einen Fahrer zu finden, der nicht diskutierte und auch nicht zu unfreundlich war.

An diesem Tag ging die Hinfahrt recht gut, aber auf der Rückfahrt erwischte er einen Taxifahrer, der auf die Aussicht, nur ein paar Euro zu verdienen, äußerst mürrisch und genervt reagierte. Ganze sieben Minuten dauerte die Fahrt. Das Taxi hielt auf der gegenüberliegenden Straßenseite an. Der Fahrer drängte den alten ungelenken Mann aus dem Taxi. Kaum hatte dieser seine Taschen aus dem Auto genommen und die Tür geschlossen, rauschte der Fahrer davon.

Mit zwei Taschen in der Hand am Straßenrand im Schnee rutschte der Patient beim Überqueren der Straße aus und verdrehte sich dabei das rechte Knie. Mit Hilfe von Passanten wurde er in die Wohnung gebracht. Dort lag er noch, als ich zwei Stunden später bei ihm zum Hausbesuch erschien. Sein Knie war geschwollen. Ich vermutete einen Schienbeinkopfbruch und erledigte alles für die notwendige Einweisung.

Die aufgeregte Schwester tröstete ich mit der Aussicht, dass ihr Bruder ja vielleicht bald wieder aus dem Krankenhaus entlassen würde. Leider hatte ich damit nicht Recht. In der Klinik ging einiges schief, es kam zu einer Infektion des operierten Schienbeinkopfbruches, eine Lungenentzündung mit letztendlich tödlichem Ausgang folgte.

Eine ungeräumte Straße, ein unhöflicher Taxifahrer und eine Klinik wurden zum Schicksal für dieses Geschwisterpaar. Einen Monat nach ihrem Bruder verstarb auch die Schwester. Ob das an ihrer Herzmuskelschwäche lag oder an der Einsamkeit im Leben ohne den Bruder, soll sich jeder selbst ausmalen.

Dr. Med. JüRgen RABE - 